\title{
A Three-Level Scheme for Current Source Conversion
}

\author{
Baiqing Yin, Baofeng Yang, Caixia Qiao, Chunjing Yang
}

Inner Mongolia Electric Power Science \& Research Institute, Hohhot 010020, China

\author{
Keywords: Multilevel Topology, Current Source Converter,Three-level Converter
}

\begin{abstract}
According to the principle of multilevel reinjection conversion, a three-level scheme of current source converter is proposed. The pulse modulation method for the new scheme is given and the waveforms of voltage and current are shown in simulation. The simulation results demonstrate the feasibility of the new topology and pulse modulation method. The output dc current in new scheme is averaged by the auxiliary branch circuits.
\end{abstract}

In comparison with the previous scheme, the rated current and change ratio of the current in branch switch during the switching transition are depressed, the interval of every branch switch being on is increased and the utilization rate of the branch switch is improved.

\section{Introduction}

A simpler multilevel concept, dc-ripple reinjection, was proposed thirty years ago for the line-commutated ac/dc converter [1]. It increases the number of pulses of the dc voltage and the number of steps of the ac current waveforms, similar to the effect as converter transformer phase-shifts. Therefore the scope of this concept is wider than that of the recent multi-terminal alternatives, as it reduces the harmonic content on the dc side and the ac side of the converter. The reinjection topology consists of multilevel voltage source converter and multilevel current source converter.

Voltage source converter, being mainly discussed in multilevel reinjection conversion, has been reported widely [2-8]. Multilevel current reinjection conversion scheme has two types in the form of the main bridge, in series and in parallel. Series in the form of the main bridge is more suitable for high voltage application $[9,10]$. Parallel in the form of the main bridge is more suitable for large current applications [11, 12].

The main bridge of the proposed three-level reinjection current source converter is in parallel form. Its reinjection circuit unit is a combination of one smoothing inductance and two switching device. This scheme is to switch periodically the equivalent load of two main bridges, distributed the constant DC current to two stepped sections having value of zero applied to the two bridges. Main bridge arms switch in the corresponding current zero range, to achieve a zero-current switching. DC output current of the main bridges was stepped change, reducing the current change ratio. The new scheme fully meets the requirements of the principle of reinjection.

The new three-level structure of reinjection current source converter is easily extended to multi-level. Compared with the main bridge topology in parallel in the literature [12], the new scheme reduces the current change ratio of switching devices and switching current capacity. This advantage increases obviously with the number of levels. This paper presents the switching control strategy to DC three-level as an example, the relationship between the AC and DC side voltage and current, and PSCAD/EMTDC for circuit simulation verification.

\section{Analysis on three-level reinjection current source converter and its working principle}

Figure 2 is a proposed three-level reinjection current-source converter topology. 


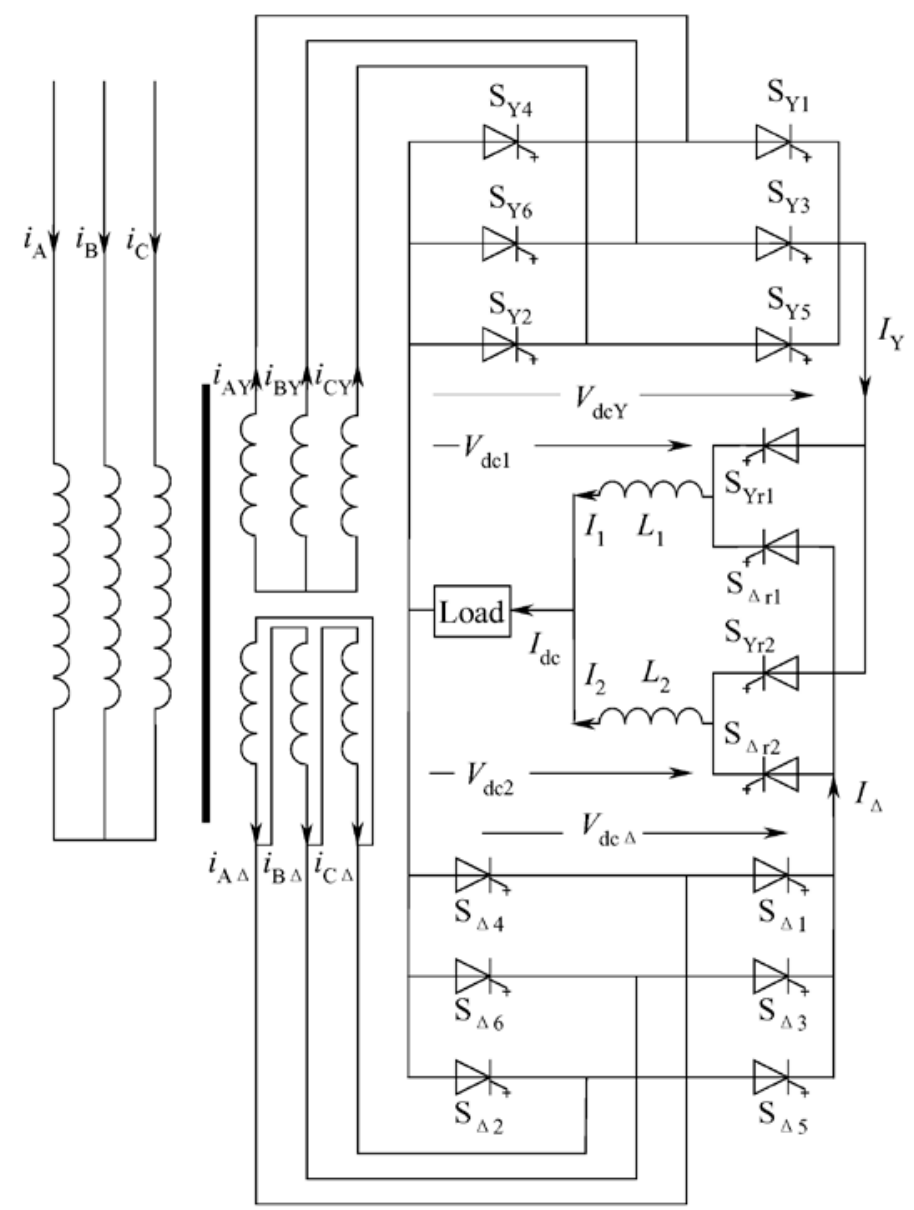

Fig.2 New topology of three-level reinjection CSC

In figure 2, all switches are reverse blocking, full-controlled devices. Transformer is an ideal transformer. Ratios of the primary to the secondary are kn $(\mathrm{Y})$ and $\mathrm{kn}: \sqrt{3}(\Delta)$. Smoothing inductors L1, L2 are sufficiently large. $\mathrm{Y}$ winding line voltage leads to a corresponding $\Delta$ winding line voltage $30^{\circ}$.

Every arm of the two main bridges opens $120^{\circ}$ in a power cycle. Triggering order is 6-1-2-3-4-5-6, and a bridge arm switch is trigged at intervals of $60^{\circ}$. The bridge side currents for the $\mathrm{Y}$ and $\Delta$ connected windings of the interface transformer have the following time domain components.

$$
\begin{aligned}
& \mathrm{i}_{\mathrm{AY}}=\left\{\begin{array}{cc}
0 & 0^{\circ} \leq \omega \mathrm{t}<30^{\circ} \\
\mathrm{I}_{Y} & 30^{\circ} \leq \omega \mathrm{t}<150^{\circ} \\
0 & 150^{\circ} \leq \omega \mathrm{t}<210^{\circ} \\
-\mathrm{I}_{Y} & 210^{\circ} \leq \omega \mathrm{t}<330^{\circ} \\
0 & 330^{\circ} \leq \omega \mathrm{t}<360^{\circ}
\end{array}\right. \\
& \mathrm{i}_{\mathrm{A} \Delta}=\left\{\begin{array}{cc}
\mathrm{I}_{\Delta} / 3 & 0^{\circ} \leq \omega \mathrm{t}<60^{\circ} \\
2 \mathrm{I}_{\Delta} / 3 & 60^{\circ} \leq \omega \mathrm{t}<120^{\circ} \\
\mathrm{I}_{\Delta} / 3 & 120^{\circ} \leq \omega \mathrm{t}<180^{\circ} \\
-\mathrm{I}_{\Delta} / 3 & 180^{\circ} \leq \omega \mathrm{t}<240^{\circ} \\
-2 \mathrm{I}_{\Delta} / 3 & 240^{\circ} \leq \omega \mathrm{t}<300^{\circ} \\
-\mathrm{I}_{\Delta} / 3 & 300^{\circ} \leq \omega \mathrm{t}<360^{\circ}
\end{array}\right.
\end{aligned}
$$




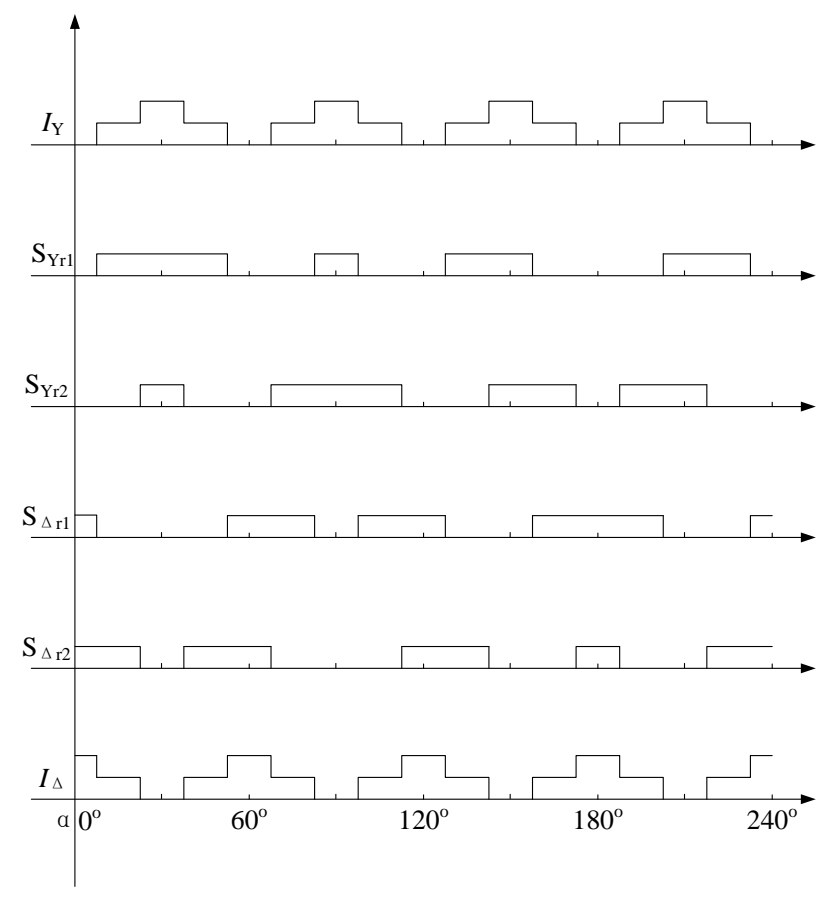

Fig.3 Firing pulses of the reinjection switches

Reinjection switch SYr1, SYr2, S $\Delta \mathrm{r} 1, \mathrm{~S} \Delta \mathrm{r} 2$ should satisfy the following relationship:

(1) The switching frequency is six times that of the main bridge switching frequency.

(2) Switch operations can provide stepped dc current with cyclical zero value for two main bridges.

(3) In a certain time period, the switching state of each switch traverses all of the normal work.

(4) SYr1 and S $\Delta \mathrm{r} 1$ interlocks, SYr2 and S $\Delta \mathrm{r} 2$ interlocks.

Conditions (1) and (2) are necessary for the DC current reinjection principle. Condition (3) ensures the reinjection switching device parameters tend to same, and averages the two branch currents. Condition (4) is necessary for this topology to work normally.

Figure 3 shows a set of available switching state.

In figure 3 , the firing angle $\alpha$ is placed in coordinate zero, the trigger pulse of the switches as shown: at any time, the firing pulses of SYr1, SYr2 superimposed exactly same to the ideal waveform of IY, the firing pulses of $\mathrm{S} \Delta \mathrm{r} 1, \mathrm{~S} \Delta \mathrm{r} 2$ superimposed exactly same to the ideal waveform of I $\Delta$. Every $240^{\circ}$ interval reinjection switches go through all the normal operation of the switching status. Wave height of each level in IY, I $\Delta$ is Idc/2, level width of $15^{\circ}$. The arms of the main bridge achieve zero -current switching.

Change cycle of IY, I $\Delta$ is $60^{\circ}$. The expression of IY in a period is

$$
\frac{\mathrm{I}_{\mathrm{Y}}}{\mathrm{I}_{\mathrm{dc}}}=\left\{\begin{array}{cc}
0 & 0^{\circ} \leq \omega \mathrm{t}<7.5^{\circ} \\
1 / 2 & 7.5^{\circ} \leq \omega \mathrm{t}<22.5^{\circ} \\
1 & 22.5^{\circ} \leq \omega \mathrm{t}<37.5^{\circ} \\
1 / 2 & 37.5^{\circ} \leq \omega \mathrm{t}<52.5^{\circ} \\
0 & 52.5^{\circ} \leq \omega \mathrm{t}<60^{\circ}
\end{array}\right.
$$

The expression of $I_{\Delta}$ in a period is

$$
\frac{\mathrm{I}_{\Delta}}{\mathrm{I}_{\mathrm{dc}}}=\left\{\begin{array}{cc}
1 & 0^{\circ} \leq \omega \mathrm{t}<7.5^{\circ} \\
1 / 2 & 7.5^{\circ} \leq \omega \mathrm{t}<22.5^{\circ} \\
0 & 22.5^{\circ} \leq \omega \mathrm{t}<37.5^{\circ} \\
1 / 2 & 37.5^{\circ} \leq \omega \mathrm{t}<52.5^{\circ} \\
1 & 52.5^{\circ} \leq \omega \mathrm{t}<60^{\circ}
\end{array}\right.
$$

A-phase current for AC side is 


$$
\mathrm{i}_{\mathrm{A}}=\frac{1}{\mathrm{k}_{\mathrm{n}}}\left(\mathrm{i}_{\mathrm{AY}}+\sqrt{3} \mathrm{i}_{\mathrm{A} \Delta}\right)
$$

The Fourier series coefficients for $\mathrm{i}_{\mathrm{A}}$ is

$$
I_{A n}=\frac{8\left[1-(-1)^{n}\right] I_{d c}}{\sqrt{3} k_{n} n \pi} \sin \frac{n \pi}{24} \cos \frac{n \pi}{6} \times\left(\cos \frac{n \pi}{6}+\frac{\sqrt{3}}{2}\right)\left(2 \sin \frac{n \pi}{6}+\sin \frac{5 n \pi}{12}\right)
$$

The amplitude of the fundamental current of $\mathrm{i}_{\mathrm{A}}$ is

$$
\mathrm{I}_{\mathrm{A} 1}=\frac{8 \sqrt{3} \mathrm{I} d \mathrm{dc}}{\mathrm{k}_{\mathrm{n}} \pi} \sin \frac{\pi}{24}\left(1+\sin \frac{5 \pi}{12}\right)
$$

The valid value of $i_{A}$ is

$$
\mathrm{I}_{\text {Arms }}=\sqrt{\frac{1}{\pi} \int_{0}^{\pi} \mathrm{i}_{\mathrm{A}}^{2}(\omega \mathrm{t}) \mathrm{d}(\omega \mathrm{t})}=\frac{\sqrt{4+\sqrt{3}}}{3 \mathrm{k}_{\mathrm{n}}} \sqrt{1+\frac{11-6 \sqrt{3}}{52}} \mathrm{I}_{\mathrm{dc}}
$$

Total harmonic distortion of transformer primary current is

$$
\mathrm{THD}_{\mathrm{I}}=\frac{\sqrt{\left(\sqrt{2} \mathrm{I}_{\mathrm{Arms}}\right)^{2}-\mathrm{I}_{\mathrm{A} 1}^{2}}}{\mathrm{I}_{\mathrm{A} 1}}=7.77 \%
$$

Figure 4 shows waveforms of the normalized currents.
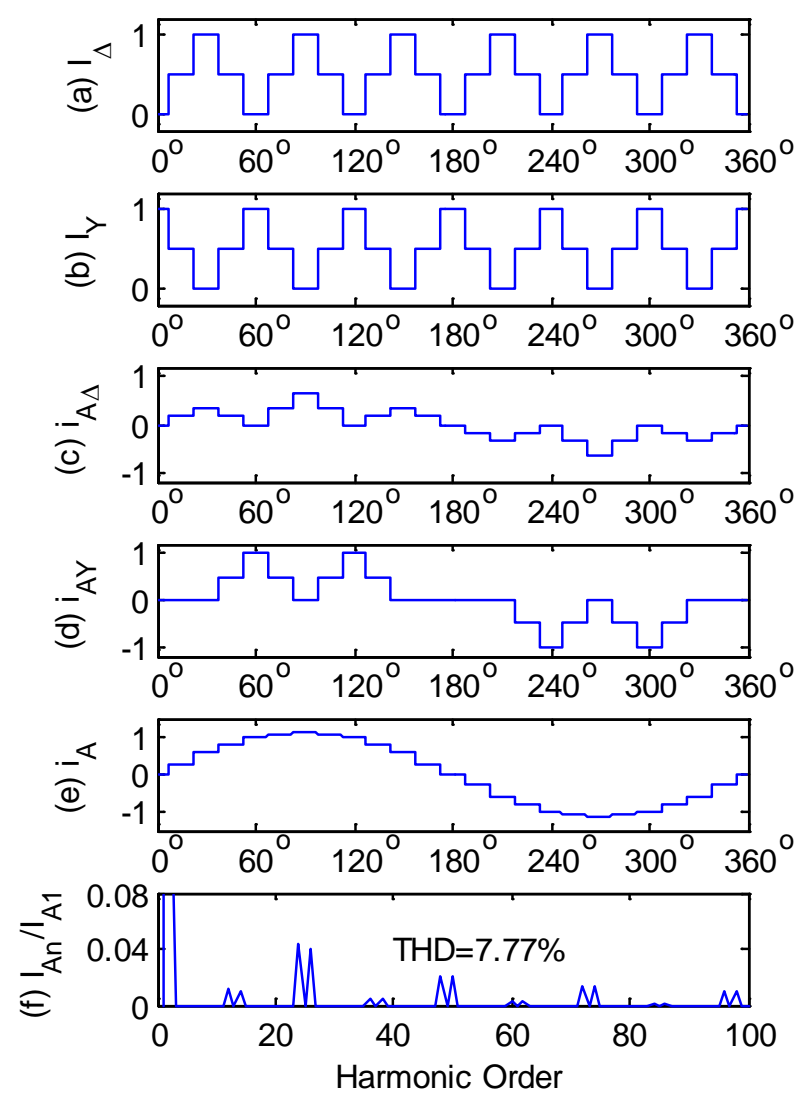

Fig. 4 Current Waveforms of the System

\section{Simulation}

To verify the new circuit topology and how it works, simulation is carried out based on PSCAD/EMTDC environment. Simulation parameter for transformer capacity is 100MVA, and its leakage inductance is $5 \%$. The primary voltage is $100 \mathrm{kV}$. The ratio of primary turns to the secondary turns, respectively, is $1: 1(\mathrm{Y})$ and $1: \sqrt{3}(\Delta)$. Inductance value of two smoothing inductors 
is taken as $0.5 \mathrm{H}$. Resistor value of the load is taken as $100 \Omega$. Firing angle is $30^{\circ}$. System simulation current waveforms are shown in Figure 5.

Simulation waveforms diagram of Figure 5 are very similar to theoretical waveforms in Figure 4, except that the step change in the current simulation waveform of a rising and falling edge transition, because the snubber circuit of the switching device to absorb and emit energy in the leakage inductance while the switching state changes. Total harmonic distortion of primary current is $8.01 \%$ in simulation, slightly larger than the theoretical value $7.77 \%$. 23 and 25 harmonics are the largest proportion.
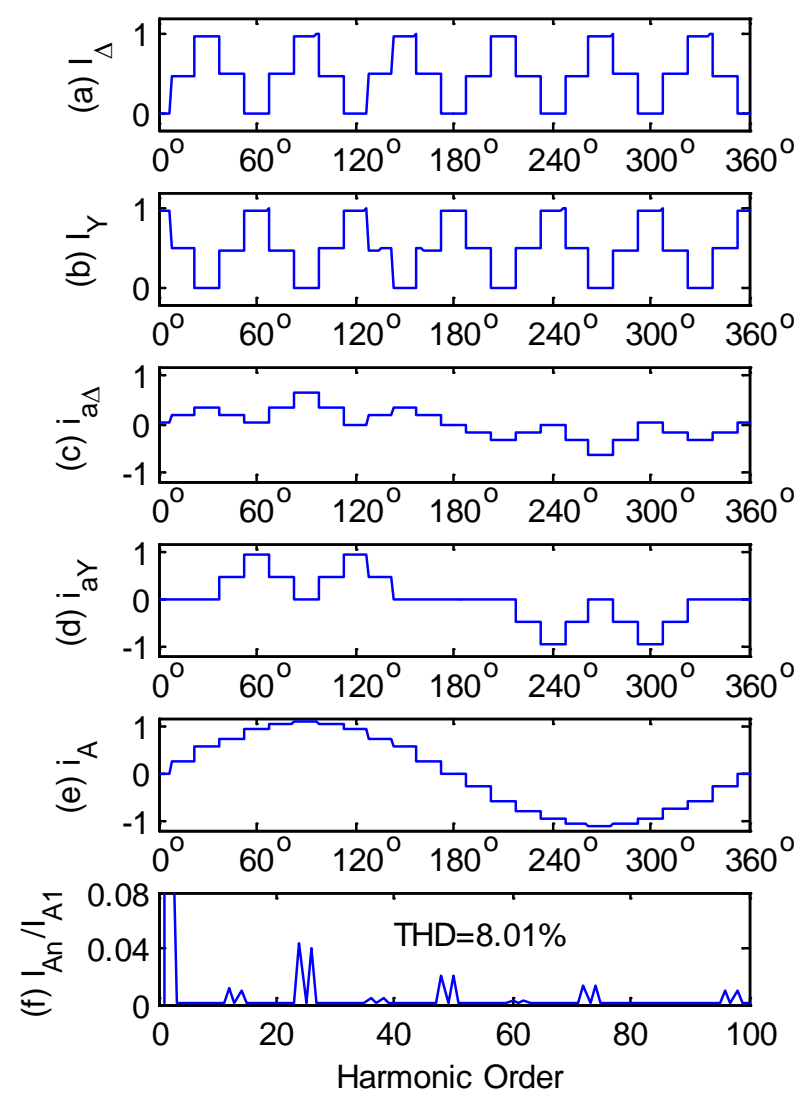

Fig. 5 Simulated Current Waveforms of the System

\section{Conclusion}

This paper proposes a novel parallel three-level reinjection current source converter scheme, shows the firing pulse modulation principle of main bridge switch and reinjection switch. The new scheme fully meets the requirements of multilevel reinjection principle, and to facilitate expanded to multilevel scheme. Compared to existing multi-tap reactors using parallel topology, reinjection switch on-state average current and the current rate of change is lower. The main bridge switches are provided reliable zero-current switching conditions. So the advantages of multilevel reinjection current source converter are more prominent.

\section{Acknowledgement}

This work was financially supported by the Inner Mongolia Power (Group) CO.,LTD Science and Technology Foundation (Project No.20130229). 


\section{References}

[1]. J.F.Baird, J.Arrillaga. Harmonic reduction in dc-ripple reinjection, IEE proceedings, Part_C, 1980, 127:294-303.

[2]. Y.H. Liu, J. Arrillaga, and N.R. Watson. A New High-Pulse Voltage-Sourced converter for HVdc Transmission. IEEE Transactions on Power Delivery, 2003, 18(4): 1388-1393.

[3]. Y.H. Liu, J. Arrillaga, and N.R. Watson. A New STATCOM Con-figuration Using Multi-Level DC Voltage Reinjection for High Power Application. IEEE Transactions on Power Delivery, 2004, 19(4): 1828-1834.

[4]. Zhang Hongtao, Song Qiang, Liu Zhongqi, et al. Real-time Digital Simulation of a \pm 50 Mvar Cascaded Statcom [J], Automation of Electric Power Systems, 2006, 30(17):19-23.

[5]. Shen Fei, Wang Yalan, Liu Wenhua, et al. Analysis and Comparison of Large Capacity Statcom [J], Automation of Electric Power Systems, 2003, 27(8): 59-65.

[6]. Xiong Yu, Hu Changshen, Cheng Dianjiang, et al. Research on a New Three-phase Direct Type Multilevel Current Source Inverter Topology, Proceedings of the CSEE, 2004,24(1): 16 3-167.

[7]. Wu Wenhui, Liu Huijin. Research Status and Development of Static Synchronous compensator. Journal of East China Jiaotong University, 2005, 22(2): 89-94.

[8]. Xing Shihui. Current Status and Future of AC Flexible Transmission Technology. Electric Power Construction, 2005, 26(8): 21-23.

[9]. Yu Yong, Zhang Xing, Ji Jianqiang, et al. Control and Analysis of High Power Current Source Multi-Converter Power System [J], Proceedings of the CSEE, 2004, 24(12): 24-28.

[10]. Bao Jianyu, Li Yuling, Ba Zhihong, et al. Research on Topology and PWM Control Method of a Three-phase Five-1evel Current-source Inverter, Proceedings of the CSEE, 2006,26(9): 71-75.

[11]. L.B. Perera, N.R. Watson, Y.H. Liu, et al. Multilevel current reinjection self-commutated HVDC converter. Generation Transmission and Distribution, IEE Proceedings, 2005, 152(5): 607-615.

[12]. Lasantha B. Perera, Yonghe H. Liu, Neville R.Watson, et al. Multi-Level Current Reinjection in Double-Bridge Self-Commutated Current Source Conversion. Power Delivery, IEEE Transactions, 2005, 20(2): 984-991. 